\title{
Dialética do cuidado humanizado na UTI: contradições entre o discurso e a prática profissional do enfermeiro*
}

\author{
DIALECTICS FOR HUMANIZED CARE IN ICUS: CONTRADICTIONS BETWEEN \\ PROFESSIONAL NURSING DISCOURSE AND PRACTICE
}

\section{DIALÉCTICA DEL CUIDADO HUMANIZADO EN LA UCI: CONTRADICCIONES ENTRE EL DISCURSO Y LA PRÁCTICA PROFESIONAL DEL ENFERMERO}

\author{
Leandro Barbosa de Pinho', Silvia Maria Azevedo dos Santos²
}

\begin{abstract}
RESUMO
Este estudo pretende desvelar contradições no cuidado humanizado do enfermeiro na UTI. Trata-se de uma pesquisa qualitativa, de orientação dialética, com sete enfermeiros, quatro familiares e um paciente em uma UTI de Adultos de um Hospital Universitário do Estado de Santa Catarina. Utilizamos a observação participativa e a entrevista semi-estruturada. O referencial teórico-filosófico baseou-se nas idéias marxistas e gramscianas de contradição. Verificou-se que o cuidado humanizado está inserido em uma complexa teia, em que o saber cuidar parece dar vazão ao estreitamento dos vínculos e o fazer cuidar segue uma estratégia impessoalizante dentro da lógica de produção de saúde parcelar e rotinizada. A dissociação entre o saber e o fazer também contempla as dificuldades em lidar com os encargos de sofrimento e as limitações profissionais-institucionais. Concluímos que o conhecimento dessa realidade seja um novo velho desafio ao enfermeiro, em busca da constante construção/reconstrução da enfermagem em termos de práticas, saberes e relações.
\end{abstract}

\section{DESCRITORES}

Unidades de Terapia Intensiva.

Cuidados intensivos.

Humanização da assistência.

Saúde do adulto.

\begin{abstract}
This study attempts to unveil contradictions in humanized nursing care in ICUs. It is a qualitative, dialectic-based study involving 7 nurses, 4 family members and one patient of the Adult ICU of the Hospital of the Federal University of Santa Catarina. Participatory observation and semi-structured interviews were applied to collect the data. Marxist and Gramscian ideas of contradiction were used as the theoretical-philosophical reference. This study demonstrates that humanized care is part of a complex network, in which care knowledge seems to give way to closer network ties, while care practice follows an impersonalized strategy within the logic of partitioned and routine health care production. The dissociation between knowledge and practice also contemplates the difficulties in dealing with the burdens of suffering and institutional-professional limitations. The conclusion is that knowledge of this reality should be a renewed, yet age-old challenge for the nurse in the search for the constant construction/ reconstruction of Nursing in terms of practice, knowledge and work relations.
\end{abstract}

\begin{abstract}
RESUMEN
Este estudio pretende develar contradicciones en el cuidado humanizado del enfermero en la $\mathrm{UCl}$. Se trata de una investigación cualitativa, de orientación dialéctica, realizada con siete enfermeros, cuatro familiares y un paciente en una $\mathrm{UCl}$ de Adultos de un Hospital Universitario del Estado de Santa Catarina. Utilizamos la observación participativa y la entrevista semi-estructurada. El referencial teóricofilosófico se basó en la ideas marxistas y gramscianas de contradicción. Se verificó que el cuidado humanizado está insertado en una complejo enmarañado, en donde el saber cuidar parece dar rienda suelta al estrechamiento de los vínculos y el hacer cuidar sigue una estrategia impersonal dentro de la lógica de la producción de salud parcelar y rutinizada. La disociación entre el saber y el hacer también contempla las dificultades en lidiar con los encargos de sufrimiento y las limitaciones profesionales-institucionales. Concluimos que el conocimiento de esa realidad sea un nuevo viejo desafío para el enfermero, en búsqueda de la constante construcción/reconstrucción de la enfermería en términos de prácticas, saberes y relaciones.
\end{abstract}

\section{KEY WORDS}

Intensive Care Units.

Intensive care.

Humanization of assistance.

Adult health.

\section{DESCRIPTORES}

Unidades de Terapia Intensiva.

Cuidados intensivos.

Humanización de la atención.

Salud del adulto.

\footnotetext{
* Extraído da dissertação "O cuidado de enfermagem na Unidade de Terapia Intensiva: contradições entre o discurso e a prática profissional", Departamento de Enfermagem, Universidade Federal de Santa Catarina, 2005. ${ }^{1}$ Enfermeiro. Professor Assistente da Universidade Federal de Mato Grosso (UFMT). Mestre em Enfermagem pela Universidade Federal de Santa Catarina (UFSC). Doutorando em Enfermagem Psiquiátrica pela Escola de Enfermagem de Ribeirão Preto, Universidade de São Paulo (EERP-USP). Apoio CNPq. Ribeirão Preto, SP, Brasil. Ibpinho@uol.com.br ${ }^{2}$ Enfermeira. Professora Doutora do Programa de Pós-Graduação em Enfermagem da Universidade Federal de Santa Catarina (UFSC). Florianópolis, SC, Brasil. azevedosm@matrix.com.br
} 


\section{INTRODUÇÃO}

O processo de hospitalização podemos considerar como um evento estressante, porém singular, para pacientes e familiares acompanhantes atendidos. No caso do processo de internamento na UTI, pode haver a emergência de uma série de sinais e sintomas de desestabilização físico-emocional. Os fatores para que isso aconteça são muitos, podendo ser citados o afastamento temporário entre eles, o risco de vida, a incerteza quanto ao tratamento e recuperação, o imaginário que ronda o sucesso e o fracasso das tentativas, bem como as limitações na prestação de suporte psicossocial|(1).

Quando se pensa em cuidado na unidade de terapia intensiva, é importante ressaltar que as profissões da saúde o contemplam como um discurso e uma prática que, coerentemente ou não, culminam em uma multiplicidade de manifestações. Cada uma das referidas profissões utiliza de seu conhecimento do mundo e de seu conhecimento específico para prestar esse cuidado. Os enfermeiros, por exemplo, utilizam-se do diálogo, da interação interpessoal, das técnicas e procedimentos para cuidar. Entretanto, em determinadas ocasiões, as formas de cuidar podem apresentar-se contraditórias, contrastando com a própria maneira de ser e de agir do profissional que cuida.

$O$ cuidado de enfermagem prestado nas unidades de terapia intensiva, de certa forma, é paradoxal. Em algumas situações, é preciso provocar dor, para que se possa recuperar e manter a vida. Em outras, não se pode falar, apenas cuidar de uma pessoa que não dá sinais de estar sendo percebida como pessoa. $\mathrm{O}$ cuidado, num caso desses, parece não implicar uma relação de troca, devido à imobilidade ou falta de diálogo e interação com o outro. Sendo assim, é possível pensar que exista, na profissão de enfermagem, uma robotização/mecanização das ações e práticas de cuidado $^{(2)}$.

Assim, o presente estudo pretende conhecer as contradições que se revelam na prestação do cuidado humanizado do enfermeiro na UTI, baseado na tese de que o cuidado pode revelar-se contraditório, refletindo-se no discurso e na prática profissional.

\section{REFERENCIAL TEÓRICO-FILOSÓFICO}

Para contextualizar as contradições do cuidado humanizado na UTI, é importante considerar as suas micro e macro-relações, tanto internas (que dizem respeito ao próprio profissional), quanto externas (no que concerne as relações deste com a realidade objetiva e social), e que influenciam na maneira de como o homem concebe o mundo, a sua realidade, o seu pensamento, a sua ação e as contradições que permeiam esse processo. Para isso, valemo-nos de leituras marxistas e gramscianas para propor a discussão deste trabalho.

A contradição pode ser vista como uma relação determinada no concreto e inserida no mundo do trabalho, estando situada no intermédio de dois objetos específicos, que se negam e excluem, mas que se complementam, tornando-se a base para o movimento da vida e da história. A contradição é formada por pólos ambivalentes, mas indissociáveis, que alteram, em maior ou em menor grau, o saber, o fazer, o ser e o pensar das pessoas ${ }^{(3-4)}$.

As contradições permeiam toda a construção do ser e do estar no mundo, fazendo parte de nós como seres humanos, como seres inseridos em um contexto histórico e social. Por ser a história um produto dos homens e estar entre os homens, a realidade social não poderia ser outra coisa a não ser o produto e a expressão dessas contradições, que também são o motor da transformação humana, da sociedade e da vida. Por serem dinâmicas no tempo e no espaço, toda a contradição se processa em uma espiral alimentada por novas contradições, influenciando as condutas, as escolhas e a própria maneira de viver dos homens ${ }^{(5)}$.

No entanto, todo o homem que atua praticamente pode não possuir uma consciência teórica de sua ação e de suas finalidades. Em algumas situações, essa mesma consciência teórica pode, historicamente, entrar em contradição com o seu agir. Quando isso acontece, cria-se uma consciência contraditória, que influencia a conduta moral dos homens de maneira intensa. A influência pode ser tão significativa, a ponto de atingir um estado de consciência que impossibilita gerar ações e escolhas, levando à passividade, à imobilização, a atitudes subalternas, ao marasmo moral e político. Entretanto, sendo a própria realidade contraditória, dentro dela existem possibilidades de ruptura com as formas de pensar e agir antagônicas, constituindo-se em um novo conhecimento de mundo, na medida em que o homem pode revê-lo, dinamizá-lo, para poder transformá-lo(6).

Dessa forma, devemos dizer que consideramos as práticas de cuidado como uma realidade histórica, que, resultante de uma sucessiva montagem de discursos, filosofias de trabalho, pensamentos e políticas, passa a ser alimentada de freqüentes contradições. Tais contradições podem influenciar as próprias condutas éticas do profissional, tornando-o, ao mesmo tempo, dinâmico, passional, ambivalente, passivo e intrigante.

\section{MÉTODO}

Trata-se de uma pesquisa qualitativa, de orientação dialética, realizada com sete enfermeiros, quatro familia- 
res e um paciente na Unidade de Terapia Intensiva de adultos de um Hospital Universitário de Santa Catarina. Para tanto, o projeto foi encaminhado, para o Comitê de Ética em Pesquisa da instituição, e recebemos o parecer favorável ao desenvolvimento do estudo (Projeto n. 200/05).

As estratégias de coleta de dados utilizadas para este estudo foram a observação participativa e as entrevistas semi-estruturadas aplicadas aos sujeitos.

A primeira etapa de coleta de dados foi feita através das observações em campo, realizadas no período de 14/ 06/2005 a 19/08/2005, totalizando 120 horas. Todos os turnos de trabalho foram observados, e os dados foram registrados em um diário de campo para serem confrontados com as informações geradas das entrevistas. Os dados gerados das notas de observação foram identificados, ao longo do texto, como N.O.

Após a coleta de dados por meio das observações, procedemos às entrevistas, dispondo de um roteiro específico para enfermeiros e outro para os familiares acompanhantes e o paciente. Para a análise dos dados, fizemos leituras e re-leituras dos textos gerados pelas mesmas, até chegar às categorias que mais apontassem o que estava sendo dito pelos informantes. Na etapa seguinte, quando já iniciávamos a fazer inferências e interpretações, chegamos à construção de dois eixos de discussão, sendo, neste estudo, trabalhada a questão da dialética do cuidado humanizado na UTI.

Foi também garantido o anonimato dos sujeitos investigados, assim como respeitada a decisão de desistência por parte dos pesquisados, conforme Termo de Consentimento Livre e Esclarecido, Resolução 196/96 do Ministério da Saúde e Código de Ética dos Profissionais de Enfermagem. Para tanto, os enfermeiros foram identificados com a letra $E$ seguida de sua ordem na entrevista (por exemplo, $E_{2}$ ). Os familiares, da mesma forma, foram identificados com a letra $F$ e o paciente investigado com a letra $P$.

\section{RESULTADOS E DISCUSSÕES}

A enfermidade vivenciada por uma pessoa não afeta apenas o seu físico, mas afeta inclusive a sua própria identidade. A doença que a acomete lhe causa um sofrimento que também atinge uma dimensão psicossocial. Por sermos seres humanos, não deixamos de sentir, de ficar preocupados com o que aceitamos ou não, com o que é culturalmente ou socialmente aceito, quando estamos doentes. É importante, portanto, que o profissional de saúde compreenda não somente o que o homem pensa, mas também o que ele sente ${ }^{(7)}$.

No entanto, como expusemos anteriormente, faz parte do atendimento intensivo prestado pelos profissionais a manutenção das condições vitais do doente, a busca de sua recuperação rápida, ou mesmo visando à cura de alguma patologia mais grave. Nesse sentido, certas facetas de cuidado transparecem. Por ser um ambiente especial, em que a gravidade, a invasividade e o risco de morte são freqüentes, parece que se cria um estereótipo de que a UTI é um ambiente hostil, negativo, que pouco produz saúde, predominando o imaginário da morte, da dor e do sofrimento:

Então eu me dei conta de que eu estava mal. Eu estou em um momento crítico da vida. E estando lá na UTI, aqueles boxes um ao lado do outro, não foi uma experiência agradável, nem bonita. Morreu o primeiro ao meu lado. E quando morre alguém ao teu lado, que está na mesma situação tua, no mesmo leito ao lado, nas mesmas máquinas, não tem como não pensar. Podia ter sido aqui. E assim aconteceu a segunda vez, a terceira vez. Durante o período que eu estive lá, três pessoas morreram. Isso é um choque muito impactante na vida $\left(\mathrm{P}_{1}\right)$.

Bom, a princípio, UTI é uma palavra que assusta [...] a hora em que eu escutei que ele tinha que ir pra UTI me deu uma tristeza muito grande, porque era uma coisa que ele não gostaria de fazer. Não pelo fato do que eu ia imaginar da UTI, mas pelo fato de que ele não queria ir. Eu fiquei muito triste, telefonei pros filhos, chorei, mas, nesse sentido, isso foi muito importante... $\left(F_{2}\right)$.

Eu fiquei muito chocada essa semana, muito triste, sabe? Tinha um rapaz de 27 anos que faleceu, estava da mesma cor que o meu marido, eu fiquei muito triste aquele dia, não me conformava, sabe? E ele era lá da nossa terra, mas ele mora aqui perto da beira-mar, faleceu essa semana $\left(F_{4}\right)$.

As falas apresentadas parecem mostrar um conjunto de expectativas e de conflitos ambivalentes nos familiares acompanhantes, fruto da cultura de um senso comum sobre a UTI. Se, por um lado, denotam uma possibilidade de receber um cuidado melhor, específico, atento, por outro, parecem revelar as suas dificuldades pessoais, assim como o sofrimento e a tristeza pela complicação do quadro clínico.

Entendemos que o senso comum que perpassa o imaginário social dos acompanhantes levanta um questionamento interessante sobre a complexidade que o processo de internamento da UTI representa para eles, mesclando-se o sentimento de pesar pela proximidade da morte com a visão negativa criada pela quantidade de aparelhagens que mantêm os pacientes vivos na unidade. Tal situação é uma realidade observada dia-a-dia pelos profissionais de saúde do setor, carecendo ser repensada e trabalhada seguidamente no interior desses espaços.

Ainda abordando o senso comum, é importante citar que ele não se resume apenas ao fato de, na UTI, haver casos graves que se encerram na dor, no sofrimento e na morte dos pacientes. $\mathrm{O}$ adoecimento nessas condições também proporciona uma experiência positiva para pacientes e familiares, que começam a valorizar pequenos sinais, antes talvez não tão importantes, individual e coletivamente. Tal fato parece criar uma polarização entre o bom e o ruim, ou, metaforicamente, um elo entre a beira do abismo e a liberdade ${ }^{(8)}$ : 
Então eu descobri uma coisa, que a UTI, na prática, é dentro de um hospital, é um lugar separado em um ambiente todo especial. O que eu descobri também? Descobri que pra ir pra UTI você precisa ter sinais de vida, mas você precisa ter sinais claros de morte. É um local em que pequenos sinais se tornam tão importantes na vida da gente, como por exemplo, lavar a boca. Quem valoriza lavar a boca? E lá, lavar a boca era o alvo do dia. Achar o momento em que eu pedia e eles concordavam $\left(P_{1}\right)$.

O senso comum envolve um conjunto de concepções de mundo que não são únicas, idênticas no tempo e no espaço, mas correspondem a todo o conhecimento reunido de maneira desorganizada, dispersa, assumindo um caráter acrítico e a-filosófico, que perpassam a história, a vida social e cultural, onde se desenvolve a individualidade moral do homem. Embora o senso comum carregue concepções individualizadas e pouco reflexivas da vida humana, já se caracteriza como o embrião de uma nova concepção de mundo, estimulando a reflexão e o repensar das idéias ${ }^{(6)}$.

Os enfermeiros da UTI estão cientes da existência de um senso comum sobre o ambiente de UTI, que permeia o imaginário das pessoas no momento da internação. Eles parecem acreditar que o referido senso comum pode ser trabalhado durante as visitas e nos horários a elas alternativos, visando à minimização das condições de sofrimento psíquico. Para eles, o trabalho com esse senso comum pode fazer parte do significado que eles atribuem ao cuidado, que, para isso, deve-se basear na interação, na visão do todo e no poder fazer pelo outro, principalmente quando este não pode fazer por ele mesmo, pela condição de adoecimento grave. Em seus discursos, isso fica característico, como pode ser verificado a seguir:

Cuidado é uma interação interpessoal, como essa nossa aqui, é uma relação interpessoal, uma relação de afetividade, de carinho, de apoio, atenção, é um relacionamento empático, um relacionamento que permeia toda a atividade da enfermagem. Na verdade, ele é o resultado final da assistência de enfermagem, e no processo de trabalho ele é um instrumento subjetivo da enfermagem $\left(\mathrm{E}_{3}\right)$.

Cuidado é ver o paciente como um todo, é poder atender às suas necessidades, é poder atendê-lo junto com a família, é tentar tornar o ambiente menos hostil possível durante a permanência na UTI, é não esquecer o que o paciente é lá fora. Eu acho que às vezes o paciente chega aqui e a gente acha que vai tirar a roupa dele, que achar aquilo uma coisa normal, sabe? Sabe lá se lá fora ele não é evangélico, ele pode não ter tirado a roupa na frente de ninguém, então eu acho que cuidado é ver a individualidade do paciente aqui na UTI, tentar tornar o ambiente menos hostil para ele $\left(E_{5}\right)$.

Tens que ver nessa totalidade o lado espiritual, a família, prestar um esclarecimento à família, faz parte do cuidado isso. Eu nunca limito a visitação, eu deixo entrar à vonta- de, dou uma satisfação pra família sobre o paciente. Eu já fui paciente, então eu sei disso, o quanto é importante receber uma visita [...] isso é cuidado, ter essa percepção. Sem dúvida a elaboração de técnicas, deixar os curativos feitos, bem cuidados, bolsas, drenagens, evitar a umidade do leito, isso tudo é cuidado, mas não se pode restringir a isso, tem que ter uma visão geral $\left(E_{7}\right)$.

O discurso dos enfermeiros intercala a concepção de cuidado integral, adotando a postura de que eles estão atentos aos cuidados diretos com os pacientes, além de estarem atentos às necessidades psicoemocionais dos familiares. Para os profissionais, o cuidado é ver a totalidade do paciente, atendendo as suas solicitações, acolhêlo, como também as expectativas e os sentimentos dos familiares acompanhantes.

O acolhimento é um tipo de relação que se produz no trabalho vivo, no encontro do trabalhador com o usuário, fundamentando-se na escuta e na receptividade, propiciando reorganizar o processo de trabalho em saúde, além de permitir englobar as diferentes demandas dos sujeitos. Ele pode ajudar na reorganização do trabalho interdisciplinar, transformando um atendimento centrado na doença em um atendimento centrado no usuário ${ }^{(9)}$.

O acolhimento dos anseios e do sofrimento humano pode auxiliar na re-significação do trabalho na UTI e do processo de internamento, minimizando as condições de sofrimento mental. O discurso que caracteriza o cuidado como uma dimensão que compreende o fazer pelo outro, a escuta atenta e a inserção da família como uma extensão das relações sociais dos pacientes parece caracterizar a intenção de organizar as práticas em torno da lógica da atenção usuário-centrada, e não somente na doença ou nas necessidades imediatas dos pacientes.

Ainda que exista uma política institucional que determine a rotina de horários para a visita dos acompanhantes, ela vem sendo flexibilizada pelos enfermeiros, na maioria das vezes. Parece que essa flexibilização, com a abertura da UTI para as visitas fora-de-hora, fortalece as relações interpessoais e corrobora as nossas afirmações supracitadas. Isso aparece nas seguintes notas de observação abaixo:

$\mathrm{E}_{2}$, enquanto estava conversando com $\mathrm{E}_{1}$, liberou a entrada da esposa de um dos pacientes para que ela assistisse ao jogo da seleção junto com ele. Enquanto $E_{2}$ ia a uma palestra, deixou claro à equipe que essa senhora estava liberada por ela, mesmo que os médicos reclamassem... (N.O.).

... uma familiar solicitou visita ao seu parente e foi prontamente atendida por $\mathrm{E}_{4}$, que lhe solicitou apenas para lavar suas mãos, deixando-a à vontade para conversar com seu parente. As dúvidas dela foram respondidas com muita atenção, como a situação do quadro clínico, além das intercorrências [...] logo em seguida, providenciou uma cadeira pra ela e a deixou um tempo na UTI (N.O.). 
Compreendemos que, dentro de uma realidade de produção de tecnologias de relações na UTI, a flexibilização de rotinas das visitas pareceu-nos fundamental para o estreitamento dos laços afetivos e para o redimensionamento desse espaço social pelos familiares. Além disso, é possível perceber que tal atitude, de certa forma, significa romper com um senso comum que visualiza a UTI como um ambiente preenchido pela fatalidade, pelo sofrimento e pela negatividade. Sendo o espaço social da UTI frio, mecanicista, em que o misto de imaginário é complexo, ao mesmo tempo ambivalente, flexibilizar uma regra seria promover a aproximação das famílias que estão distanciadas, ao invés de mantê-las afastadas, para permitir a recuperação do estado de saúde dos pacientes junto com os seus vínculos interpessoais.

No entanto, os enfermeiros convivem diariamente com a alta tecnologia, com o excesso de atividades diretas para com os pacientes dependentes, além do esforço para destinar um espaço de acolhimento e escuta aos acompanhantes na UTI. Parece que os profissionais têm consciência disso, principalmente quando o assunto é lidar com sofrimento do outro que enfrenta uma doença grave e que pode implicar risco de vida mediato/imediato. Nesse sentido, revela-se uma contradição interessante no que tange ao cuidado humanizado nos horários das visitas e nos horários extras oferecidos, com a flexibilização das rotinas pelos enfermeiros:

\footnotetext{
A visita foi liberada no horário, e pude perceber que os familiares, principalmente os dos pacientes mais graves, não mantinham contato com a enfermagem. Uma familiar estava chorando à beira do leito e o técnico estava preocupado com a preparação das medicações. $E_{2}$ estava conversando com o médico, resolvendo a alta de um paciente internado e providenciando a internação de outro (N.O.).
}

Um familiar solicitou autorização para entrar, e foi informado por $\mathrm{E}_{5}$ de que a visita era só no horário. Antes disso, chegou uma nova paciente proveniente do $\mathrm{BC}$. $\mathrm{E}_{5}$ se dirigiu rapidamente para colocar os eletrodos e os equipamentos. A equipe se voltou à ela também [...] Enquanto a visita estava sendo liberada, enfermeiros e técnicos estavam envolvidos com a organização da paciente nova. Não houve contato com os familiares em visita (N.O.).

Os familiares podem ficar expostos ao isolamento social, assim como os profissionais podem distanciar-se das reais necessidades de cuidado físico e emocional. $\mathrm{Na}$ UTI, o cuidado, por mais que se pense nas estratégias de atenção humanizada, parece continuar insuficiente, frente às demandas psicossociais, já que a família ainda é naturalmente distanciada do paciente em função da gravidade do quadro e das formas de intervenção terapêutica quase que imediatas, além de invasivas ${ }^{(8 ; 10-11)}$.

Os enfermeiros, por princípio, valorizam a participação dos familiares na recuperação dos pacientes. Eles acreditam na presença do familiar como um valor adicio- nal ao tratamento, tanto que eles oferecem a flexibilização de algumas rotinas da unidade, para que esse contato ocorra. Porém, poderia dizer que eles se dedicam diretamente aos seus clientes de maneira limitada. Para alguns profissionais, o pouco envolvimento com os acompanhantes justifica-se pela falta de tempo para se dedicarem integralmente a eles, e pela utilização do horário de visita como um momento de entrega, para que o seu familiar o possa cuidar, vigiar, ficar atento. Assim, os enfermeiros se apropriam desse tempo como um período de fuga, para descansar, para tomar um café, para aliviar as suas próprias tensões e para reunir a equipe:

\begin{abstract}
Sinceramente, com os parentes dos pacientes é meio complicado, porque é um horário que a gente está sempre fazendo alguma coisa, quando eles chegam, e que às vezes a gente usa como fuga, na verdade, sinceramente te falando, sabe? Ah, está com o parente ali, então vamos lá tomar um café, ou vou lá fazer outra coisa, saio daqui, para que não façam perguntas, alguma coisa assim. É um horário de fuga, não só meu, mas acho que de todo mundo, então essa comunicação é meio complicada $\left(E_{1}\right)$.
\end{abstract}

... a questão da visita me incomoda muito, a gente percebe que a visita entra, vai diretamente ao leito e encontra seu familiar todo edemaciado, cheio de tubos, e muitas vezes você não está ali do lado. Então eu acredito que se a gente tivesse um serviço de psicologia ou serviço social mais atuante aqui dentro, a gente poderia trabalhar um pouco mais a questão do acompanhante. Eu acho que a gente poderia estar trabalhando com a sala de espera, que é uma coisa super importante, explicar o que acontece com o paciente, isso é uma dificuldade. Fazer um grupo, a gente já tinha pensado nisso, mas é a questão do tempo pra fazer isso... $\left(\mathrm{E}_{6}\right)$.

Diante disso, pensamos que o cuidado humanizado tem as suas contradições desveladas no conjunto do processo de trabalho do enfermeiro na UTI. A flexibilidade apontada nas notas de campo e nos relatos dos profissionais tem sido uma porta-de-entrada de acolhimento às manifestações do sofrimento físico/psíquico de pacientes e acompanhantes, em todas as suas dimensões. No entanto, o espaço convivencial não vem contemplando o aprofundamento do contexto intersubjetivo, continuando a predominar a superficialidade da interação, como uma dificuldade pessoal do enfermeiro. Isso é reforçado pela rotina institucional que o obriga a cumprir, mesmo diante da possibilidade de flexibilização, determinadas atividades burocráticas e diretas com os pacientes, como parcela de seu processo de trabalho. Isso parece mais distanciá-lo do contato pessoal com seus clientes, do que o aproximá-lo.

Os relatos parecem constatar que os enfermeiros conhecem o significado e a importância da empatia no cuidado de enfermagem, mas a prática levanta as dificuldades pessoais/interpessoais para administrar e lidar com os encargos de sofrimento do outro. Na relação de empatia, é importante que clientes e profissionais se situem e se 
reconheçam, compartilhando vivências, atitudes, medos, inseguranças e dificuldades ${ }^{(12)}$. Marcante no discurso dos enfermeiros acerca do cuidado, no entanto, a relação de empatia pode transformar-se em uma relação patológica, para a qual o enfermeiro utiliza a barreira psicológica, para evitar o seu próprio desgaste emocional. Assim, o processo empático parece desenvolver-se no discurso, sem que, na prática, os enfermeiros se dêem conta de que ele deve ser uma complementaridade para com o outro, e não uma absorção da realidade deste outro, como se fosse parte da sua vida.

As atividades dos profissionais de saúde que trabaIham no hospital favorecem uma concepção do sofrimento como natural, por parte desses profissionais. A dificuldade em estabelecer um equilíbrio entre vida e morte, saúde e doença, cura e óbito é uma constante, e faz com que os trabalhadores tenham potencial dificuldade em administrar o trágico. Por isso, pode-se criar um espaço de despersonalização e de afastamento da realidade dos pacientes $^{(13-14)}$.

A casuística que determina as ações de cuidado dos enfermeiros contrasta com o discurso de que, na UTI, é preciso individualizar o cuidado e priorizar o atendimento às necessidades dos doentes. A dialética que concretamente se cria entre o saber cuidado e ofazer cuidado, nesse setor, parece trazer à tona as dissociações existentes entre o pensamento e a ação profissional do enfermeiro. O saber cuidado atenderia o todo, a complexidade do adoecimento e as necessidades do paciente e de sua família - presentes no discurso, mas muitas vezes prescindindo do feedback necessário por parte das famílias e dos pacientes - este último, no entanto, nem sempre possível em UTI. Por outro lado, o fazer cuidado seguiria a rotina de procedimentos, a complementação da atividade do técnico de enfermagem, além de cuidados imediatos - presentes nas práticas implementadas na UTI. A fala de $E_{1}$ mostra essa característica:

Eu chego e pego o plantão, confiro as gavetas dos específicos [...] é um cuidado, porque eu tenho que saber se está tudo conferido ou não. Dali eu vejo os pacientes, avalio eles da cabeça aos pés, faço os curativos, já avaliando o cuidado com relação às feridas, curativos, inserções de cateteres e tudo o que tu imaginar. Eu faço toda essa avaliação, escrevo nas evoluções. Confiro a gaveta no final e passo o plantão. Mas eu faço tudo: faço medicação, isso é um cuidado, eu faço curativo, vejo se o curativo que eu fiz está legal, se está funcionando, se não, é um cuidado, sei lá, ponho botinha, penso em coisas que eu possa estar inventando, isso tudo é legal, criativo e é um cuidado $\left(\mathrm{E}_{1}\right)$.

O contraste entre o pensar e o agir, ou seja, a coexistência de duas concepções de mundo, uma que se manifesta por palavras e a outra pela ação efetiva, nem sempre se deve à má-fé. A má-fé poderia ser uma explicação satisfatória para alguns, embora incipiente e isolada. Essa manifestação de contradições que se reflete na dissociação do complexo saber-fazer seria uma expressão de contrastes mais profundos, de natureza históricosocial ${ }^{(6)}$. Caso pensarmos nessa possibilidade, é possível perceber que a consciência contraditória tem suas raízes reveladas em uma lógica de atividade parcelar, fruto da manutenção de um sistema de relações que acompanha as orientações nightingaleanas do processo de profissionalização da enfermagem. Tal situação confere, até hoje, a característica peculiar de um enfermeiro multifuncional, que deve assistir, gerenciar, ensinar e cuidar sem, por vezes, haver a articulação dessas habilidades profissionais.

A dialética entre o saber e o fazer cuidado é uma relação que, em muitos momentos, como foi apresentado, se nega a si mesma, contrapondo-se, mas não se excluindo, exigindo de pacientes, familiares acompanhantes e dos próprios enfermeiros um manejo especial da realidade produzida/reproduzida no contexto assistencial. A reflexão dessa realidade e o conhecimento das contradições teórico-práticas perpassam momentos favoráveis e desfavoráveis nas relações interpessoais. Pensamos que o conhecimento desse contexto pode ajudar na constante reformulação e transformação do cuidado nas unidades de terapia intensiva.

\section{CONSIDERAÇÕES FINAIS}

O recorte feito no estudo, tomando-se como referência o cuidado humanizado, pretendeu mostrar que a continuidade das contradições no discurso e na prática do enfermeiro caminha paralelamente com a sua ruptura, como se pôde perceber no que diz respeito à flexibilização das rotinas institucionais. A tendência de se aproximar pacientes e familiares para reforçar vínculos e tentar minimizar as condições de sofrimento físico/mental, em alguns momentos, esbarra na lógica da atividade parcelar, o que também torna confuso o discurso do profissional que defende o seu cuidado.

Ao que parece, o saber cuidar tem dado vazão ao estreitamento dos vínculos interpessoais para minimizar as condições de sofrimento físico/mental, ao mesmo tempo em que o fazer cuidar os distancia, por meio das estratégias implementadas pelos enfermeiros dentro de uma lógica de produção de saúde parcelar e rotinizada na UTI.

Percebemos que a relação estabelecida entre o saber e o fazer diante do processo de internamento na UTI sugerem que o cuidado de enfermagem esteja inserido em uma complexa teia, que se move em um ritmo dialético, preenchida de dificuldades pessoais, profissionais e necessidades institucionais. Entendemos que o conhecimento dessa realidade é um novo velho desafio a ser repensado pelo enfermeiro, para que possa possibilitar a constante construção/reconstrução da profissão de enfermagem em termos de práticas, saberes e relações. 


\section{REFERÊNCIAS}

1. Gala MF, Telles SCR, Silva MJP. Ocorrência e significado do toque entre profissionais de enfermagem e pacientes de uma UTI e Unidade Semi-Intensiva cirúrgica. Rev Esc Enferm USP. 2003;37(1):52-61.

2. Souza LNA. A interface da comunicação entre enfermagem e as(os) clientes em uma unidade de terapia intensiva [dissertação]. Florianópolis: Departamento de Enfermagem, Universidade Federal de Santa Catarina; 2000.

3. Giovanni G. O método dialético. In: Anais do 30 Seminário Nacional de Pesquisa em Enfermagem; 1984 abr. 3-6; Florianópolis, SC, Brasil. Florianópolis: Ed. UFSC; 1984. p. 161-71.

4. Konder L. O que é dialética. 4a ed. São Paulo: Brasiliense; 2003.

5. Marx K, Engels F. A ideologia alemã. São Paulo: Martins Fontes; 1989.

6. Gramsci A. Concepção dialética da história. 10ạ ed. Rio de Janeiro: Civilização Brasileira; 1995.

7. Silva MJP. Comunicação tem remédio: a comunicação nas relações interpessoais em saúde. São Paulo: Loyola; 1996.

8. Lemos RCA, Rossi LA. O significado cultural atribuído ao centro de terapia intensiva por clientes e familiares: um elo entre a beira do abismo e a liberdade. Rev Lat Am Enferm. 2002;10(3):345-57.
9.Coimbra VCC. O acolhimento no Centro de Atenção Psicossocial [dissertação]. Ribeirão Preto: Escola de Enfermagem de Ribeirão Preto, Universidade de São Paulo; 2003.

10. Albístur MC, Bacigalupo JC, Gerez J, Uzal M, Ebeid A, Maciel $M$, et al. La familia del paciente internado en la unidad de cuidados intensivos. Rev Med Urug. 2000;16(3):243-56.

11. Nascimento ERP. Acolhimento no espaço das relações na unidade de terapia intensiva [tese]. Florianópolis: Departamento de Enfermagem, Universidade Federal de Santa Catarina; 2003.

12. Kantorski LP, Pinho LB, Saeki T, Souza MCBM. Relacionamento terapêutico e ensino de enfermagem psiquiátrica e saúde mental: tendências no Estado de São Paulo. Rev Esc Enferm USP. 2005;39(3):317-24.

13. Pitta AMF. Hospital: dor e morte como ofício. 2a ed. São Paulo: Hucitec; 1996.

14. Pauli MC, Bousso RS. Crenças que permeiam a humanização da assistência em unidade de terapia intensiva pediátrica. Rev Lat Am Enferm. 2003;11(3):280-6. 